\title{
Against the universal phasehood of nP: Evidence from the morphosyntax of book titles
}

\section{David Erschler*}

Languages vary as to whether DPs used as book titles (such as Alice in Wonderland, Harry Potter and the Philosopher's Stone, etc.) can be assigned case and trigger agreement. In languages where they do participate in case and agreement relations, book (and movie) titles form a subsystem with very peculiar properties. I argue that when used as a title, any XP gets embedded in a new $\mathrm{nP}$ which projects a DP. Phasehood properties of nPs vary across languages, which leads to the variation in the agreement properties of book titles. However, even in languages that normally require lexical DP titles to trigger agreement and be assigned case, personal pronouns and other functional are exempt from this. I argue that this is related to the fact that participation in case assignment and agreement makes the index and the phifeatures of a pronoun visible on the LF thus creating an interpretational conflict.

Keywords: syntax; distributed morphology; typology; noun phrases; agreement; phases; pronouns

1. Introduction. Book (or movie) titles form a subsystem with rather peculiar properties that distinguish them from regular DPs. While in English the contents of a title is completely invisible to agreement processes, which is to say, a book title can only agree in the (presumably default) 3rd person singular (1a), this is far from being so cross-linguistically. The Russian sentence in (1b) shows that a plural DP title triggers plural agreement when used as a subject, while the sentence in (1c) shows that titles receive morphological case, in this context, the instrumental assigned by the preposition nad 'above, over'.

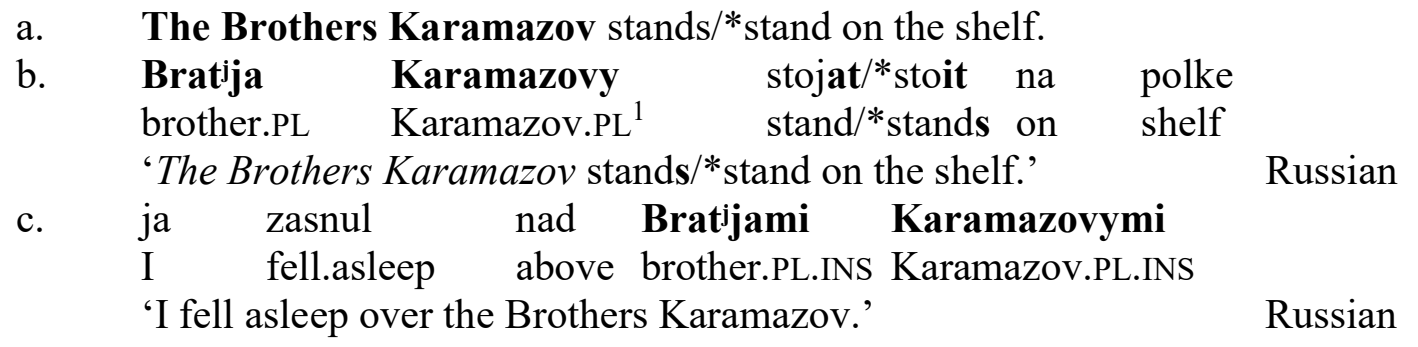

\footnotetext{
* I thank Jeremy Hartman who attracted my attention to the stark difference between English and Russian in the morphosyntax of titles, as well as Rajesh Bhatt, Seth Cable, Troy Messick, Ekaterina Vostrikova, and the audiences at the Fall 2016 UMass Syntax Seminar and LSA 2018 for their comments and discussion. I am grateful to my Russian speaking friends, too numerous to be listed here, who patiently answered the never-ending questions I had been posting on Facebook. For judgments about other languages, I thank Gašper Beguš, Sakshi Bhatia, Hagen Blix, Liza Dolidze, Natia Dundua, Gisbert Fanselow, Alex Göbel, Martin Haspelmath, Henri Israelyan, Jyoti Iyer, Aslan Kasaev, Isa Kerem, Seppo Kittilä, Elizaveta Kochieva, Andzhela Kudzoeva, Agnes Korn, Daniel Margulis, Jon Ander Mendia, Aleksei Nazarov, Deniz Özyıldız, Markus Pöchtrager, Jenneke van der Wal, and Philipp Weisser. Author: David Erschler, University of Massachusetts Amherst (erschler@gmail.com).

${ }^{1}$ Glosses: ABL ablative; ACC accusative; ANIM animate; AUX auxiliary; COMP complementizer; DAT dative; DEF definite; DIM diminutive; DU dual; F feminine; GEN genitive; INAN inanimate; INS instrumental; LOC locative; NEG negation; NOM nominative; OBL oblique; PL plural; PREP prepositional case; PRS present; PRTC participle; PST past; QNT quantitative form; SG singular. All unsourced data come from my own research.
} 
In this paper, I explore the cross-linguistic behavior of book titles on the basis of a small convenience language sample. I argue that their varying ability to be assigned morphological case and to trigger non-default verb agreement is related to the variation in the phasehood status of the $\mathrm{nP}$ in different languages. In the interests of space, I restrict my attention to agreement with verbs, leaving out adjectival agreement.

Much of the current literature in Distributed Morphology assumes that the $\mathrm{nP}$ is a phase in the sense of Chomsky (2001), see e.g. Marantz (2007); Embick \& Marantz (2008); Kramer (2015). I address cross-linguistic variation in case and agreement properties of title DPs and show that, under the standard assumptions of DM, an additional layer of the nP and DP structure must be merged in titles. Case and agreement properties of title DPs in some languages testify against the phasehood of this $\mathrm{nP}$ layer. To distinguish an XP qua a regular XP and its functions as a title, I will use the terms title DP and underlying XP.

The rest of the paper is organized as follows. In Section 2, I lay out the data regarding cross-linguistic variation in the case and agreement properties. In Section 3, I formulate the main proposal of the paper. In Section 4, I show that even in languages such as Russian, where titles normally trigger verb agreement and receive case, this is impossible for personal pronouns and nearly impossible for some other functional DPs. Section 4 concludes.

2. Cross-linguistic properties of titles: lexical DPs. In this section, I overview the patterns of case assignment and agreement that were attested in the language sample. For the expository purposes, I restrict my attention to lexical underlying DPs. The behavior of functional underlying DPs will be addressed in Section 5.

In the discussion, I will use the terms default/lexeme-specific case marking and default / lexeme specific agreement. While the term "default agreement" is standard (and default agreement surfaces as $3 \mathrm{sg}$ in all the languages of the sample), the term "default case marking" probably deserves some comment. By this, I mean the choice of case marking that disregards the lexeme specific information (such as, e.g., animacy, exceptional allomorphy patterns or suppletion), thus treating the lexeme as an abstract noun of a given phonological form.

We observe the following combinations of these features:

- Type I: No case marking; default agreement;

- Type II: Default case marking; default agreement;

- Type III: Non-default case marking; default agreement;

- Type IV: Non-default case marking; non-default agreement.

The remaining logically possible combinations, that is, default or absent case marking and non-default agreement, have not been attested. Given the small size of the sample, I am reluctant to seek a principled explanation for this gap. In the remainder of the section, I illustrate each of the attested types.

2.1. No CASE MARKING; DEFAUlT AGREEMENT. English, of course, instantiates this type. Such behavior is not unique to English: Dutch behaves in the same manner ${ }^{2}$.

\footnotetext{
${ }^{2}$ Admittedly, for languages with no overt case marking on lexical DPs, such as Dutch and English, it is difficult to tell whether they belong to Type I or Type II.
} 


$$
\begin{array}{lllll}
\text { "De Avonden" } & \text { staat } / * \text { staan op } & \text { de } & \text { plank } \\
\text { the } & \text { evenings } & \text { stands } / * \text { stand on } & \text { the } & \text { shelf }
\end{array}
$$

'The Evenings stands on the shelf.'

Dutch

Such agreement can be interpreted either as semantic (a book being a single entity), or as default. The question about how to distinguish these two interpretations is most likely moot.

The situation with case assignment in English and Dutch is rather trivial, given that lexical DPs are unable to bear overt case marking in these languages. The behavior of Basque, which also disallows number agreement $(3 \mathrm{a})$, is much more interesting in this respect: there, despite the existence of a rich morphological case system, titles do not bear overt case marking: we would expect the ergative to appear on 'the brothers Karamazov' in (3b), given that it is the subject of a causative. However, in actuality it is absent.
a.
Karamazov
anaiak
apal-ean
dago
'The Brothers Karamazov stands on the shelf.'
Basque
b.

\section{Karamazov anaiak lokartu n-a-u}
Karamazov brother.PL sleep AUX.1SG.ABS-root
'The Brothers Karamazov put me to sleep.'
Basque

2.2. Default CASE MARKING; DEFAUlt AGREEMENT. One example of a language of this type is Georgian. inanimates and animates differ in Georgian in that inanimates cannot trigger plural agreement with verbs, and, furthermore, certain position verbs are only compatible with animates. This phenomenon can be treated as agreement in animacy. For instance, the verb devs 'lies' can be only used with inanimate entities, as the contrast between (4a) and (4b) shows.
a. c'ign-i
magida-ze
$\operatorname{devs} /{ }^{*} c^{\prime}$ evs
book-NOM
table-on
lies
'The book lies on the table.'
b. bavšv-i login-ze c'evs/*devs
child-NOM bed-on lies
'The child lies on the bed.'

Georgian

Georgian

On the other hand, titles behave as inanimates even if the underlying DP is plural animate, as the word kalebi 'women' in (5), which in the capacity of a title requires the verb devs that is only compatible with inanimates.

$\begin{array}{lcl}\text { kal-eb-i } & \text { taro-ze } & \text { devs } \\ \text { woman-PL-NOM } & \text { shelf-on } & \text { lies } \\ \text { 'Women lies on the shelf.' } & \end{array}$

Georgian

In the Ossetic languages, the case marking does not trigger allomorphy in lexical nouns, so the case marking is automatically default. Moreover, these languages exhibit DOM: definite animates receive morphological case, the oblique, when used as direct objects, whereas any inanimates normally do not. Titles behave as inanimates: in (6a) the DP 'partisans' refers to actual persons, whereas in $(6 \mathrm{~b})$ it is used as the title of a film. Accordingly, it stays in the nominative. 
(6)
Iron Ossetic
a. partizan-t-ə fedton
partisan-PL-OBL I.saw
'I have seen the partisans.'
b. partizan-te fedton
partisan-PL.NOM I.saw
'I have seen The Partisans.'

Plural DPs cannot trigger plural agreement when used as titles (7b), unlike plain DPs (7a).
a. partizan-te lew-ənc/*-ə
partisan-PL stand $/ *$ stands
'The partisans (persons) stand/are standing.'

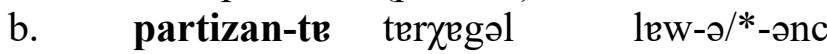
partisan-PL shelf.SUP stands/*stand
'The Partisans stand on the shelf.'

Iron Ossetic

Iron Ossetic

2.3. NON-DEFAUlT CASE ASSIGNMENT; DEFAUlT AGREEMENT. In Finnish, case assignment (which preserves the morphological class of the noun ${ }^{3}$ ) is obligatory $(8 \mathrm{a})$, whereas number agreement is impossible on the title reading $(8 b)^{4}$.
a. olen
lukenut
AUX.1SG
read.PRTC
Jäniksen
vuoden
'I've read The Year of the Hare.'
hare.GEN year.GEN
b. Paratiisisaaren vangit on hyllyssä
Paradise.island.GEN prisoner.PL is shelf.LOC
'The Prisoners of the Paradise Island is on the shelf.'

Finnish

Finnish

In German, while case marking is obligatory (9a), number agreement is rejected by many speakers (9b). This shows that case assignment and number agreement are separate processes.
a
Ich hab
I have
$\operatorname{dem} / *$ das
"Anderen
Geschlecht"
DEF.DAT $/ *$ DEF.NOM other
gender
gewidmet
dedicated
'I have dedicated an essay to The Other Gender.'
$\begin{array}{lll}\text { b. "Buddenbrook-s" } & \text { steht/?stehen auf dem Regal } \\ \text { stands/?stand on the shelf }\end{array}$
'The Buddenbrooks stands on the shelf.'
German

einen Essay

an essay

2.4. NON-DEFAULT CASE ASSIGNMENT; NON-DEFAULT AGREEMENT. In Russian, number (10a) and gender (10b) agreement of the verb with the underlying lexical DP is obligatory. Likewise, any lexical DP title is case-marked ${ }^{5}$ according to its declension class (10c). For masculine animates, the accusative is syncretic with the genitive, while for inanimates it is syncretic with the nominative, Timberlake (2004: 165-166). If an animate DP is used as a title, it retains the animate declension, as 'idiot' in (10c).

\footnotetext{
${ }^{3}$ The alternation -si-/-de- in vuosi year.NOM vs. vuoden year.ACC/GEN is not automatic: compare lasi glass.NOM vs. lasin glass.ACC/GEN; huusi 'outhouse.NOM' vs. huusen 'outhouse.ACC/GEN', kuusi 'spruce.NOM' vs. kuusen 'spruce.ACC/GEN', etc. The fact that (Swedish) loans such as lasi and huusi do not exhibit this alternation, shows that it is not the morphonological default. I thank Jim Cathey and Ethan Poole for a discussion of this point.

${ }^{4}$ The plural form of the copula, ovat, forces the literal reading of the DP, i.e. where actual humans are placed on the shelf.

${ }^{5}$ The observation that in Russian lexical DP titles are obligatorily case marked has apparently first been made by Matushansky (2013)
} 

a.
Bratija
Karamazovy stojat $/$ *stoit na
brothers Karamazov.PL stand $/ *$ stands on shelf
'The Brothers Karamazov stands/*stand on the shelf.'
b. Anna Karenina vyšl-a v 1878 g.
Anna.F Karenina.F appeared-F in 1878 y.
'Anna Karenina appeared in 1878.'
$\begin{array}{llll}\text { c. } & \text { ja crital } & \text { idiot-a } \\ & \text { I } & \text { read } & \text { idiot-ACC/GEN }\end{array}$
'I've read The Idiot.'

polke

Russian

Russian

It can be added that the tendency to incorporate titles into the syntactic structure is very strong: Kholodilova (2013) presents a wealth of examples found on the web where non-DP titles show nonetheless agreement or case marking of some nouns within the underlying XPs. It is likely that many of these examples are instances of grammaticality illusions in the sense of Philips et al (2013): for instance, in a title whose underlying XP is a sentence, e.g. such as (11a), the (nominative) subject of the sentence would receive a case assigned by the ambient clause, such as the dative in (11b) assigned to the subject 'cranes' by the verb 'to give'.
a. letiat
žuravli
fly.PRS.3PL
cranes.PL.NOM
'Cranes are flying.' (a movie title)
Russian
b. $\quad[$ letiat
žuravliam] dali
priz
fly.PRS.3PL cranes.PL.DAT they.gave prize
'They gave a prize to Cranes are flying. ${ }^{6}$, Russian

Slovenian behaves in the same manner as Russian ${ }^{7}$ : it requires the title do be case marked (12a), and has the verb agree with the subject in number (12b). Moreover, unlike Russian, Slovenian has preserved the dual, Herrity (2000:37), and in the contexts where agreement in the dual would be required for the underlying DP as for 'the Master and Margarita' in (12c), it has to be used for the title as well.

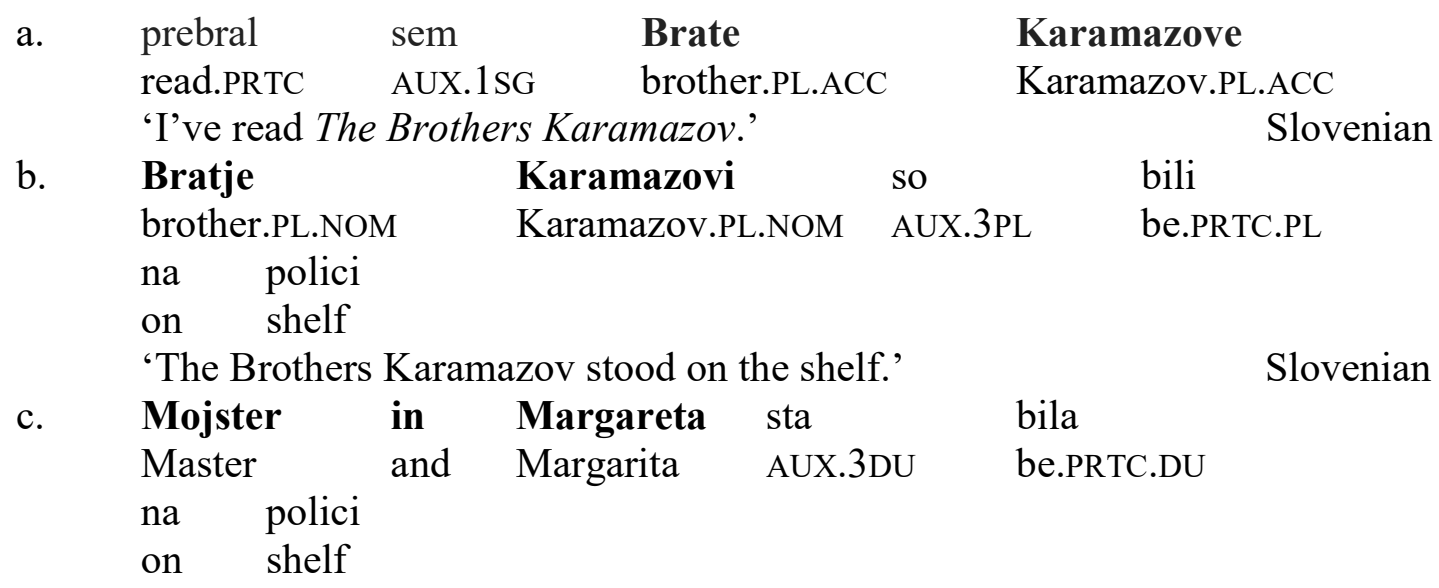

'The Master and Margarita stood on the shelf.'

Slovenian

\footnotetext{
${ }^{6}$ Based on (2) from Kholodilova (2013). I am obliged to Maria Kholodilova for sending me the handout.

${ }^{7}$ The test with animacy, however, is not informative, because in Slovenian, unlike in Russian, names of inanimate entities based on animates retain the animate class, e.g. cigan-ček 'gipsy mushroom', lit. Gipsy-DIM 'little Gipsy', retains animacy, see many more examples of this type in Herrity (2000:34-35).
} 
To recapitulate, in languages of this type lexical title DPs behave essentially as their underlying DPs. Some qualifications to this will be introduced in Section 3.1 below.

2.5. SUMMARY. The data we have seen show that languages vary widely in the extent to which they "encapsulate" title DPs. Table 1 summarizes the data from the sample.

\begin{tabular}{lll} 
Language & Case Marking & Agreement \\
\hline Type I & & \\
English & N/A & Default \\
Dutch & N/A & Default \\
Basque & Null & Default \\
Type II & & \\
Hebrew & Default & Default \\
Turkish & Default & Default \\
Georgian & Default & Default \\
Iron Ossetic & Default & Default \\
Hindi & Default & Default \\
Type III & & \\
German (some speakers) & Non-default & Default \\
Finnish & Non-default & Default \\
Type IV & & \\
German (some speakers) & Non-default & Non-default \\
Russian & Non-default & Non-default \\
Slovenian & Non-default & Non-default \\
Polish & Non-default & Non-default \\
Eastern Armenian & Non-default & Non-default
\end{tabular}

Table 1: Table showing some data about something

The question arises as to why title DPs differ so starkly from regular DPs.

3. Proposal. In this section, I argue for a uniform structure of title DPs: I propose that in a title, additional $\mathrm{nP}$ and DP layers are merged on top of the underlying XP. Furthermore, I propose that the $\mathrm{nP}$, in some languages, does not have to be a phase and tie the variation in case and agreement properties of titles to the cross-linguistic variation in the phasehood properties of nPs.

3.1. THE INTERNAL STRUCTURE OF TITLES. Book titles, no matter what category their underlying XP belongs to, evidently have the distribution of DPs (13).

$$
\begin{aligned}
& \text { a. } \quad \text { I have read Run, Rabbit, Run. (CP)/ To Kill a Mockingbird (TP) } \\
& \text { /Remembering the Things Past (VP)/If }\left(\mathrm{C}^{0}\right) \\
& \text { b. ja ne čital }[\text { što delati] }(\mathrm{CP}) \\
& \text { I NEG read what to.do } \\
& \text { 'I haven't read What Is to Be Done?' Russian }
\end{aligned}
$$

I propose to account for this fact by positing that an additional DP layer is merged to an XP when it is used as a title. Morphological evidence for positing such a D layer in titles comes from languages that are able to overtly case mark titles even when their underlying category cannot be assigned case, i.e. when it is not a DP. For instance, in Hebrew, CPs used as the complement of a transitive verb cannot be case marked, the case-marked DP 'the book' in (14a) with the sentential complement 'that horses eat straw' in (14b). 
(14)
a. karati et ha-sefer
I.read ACC the-book

'I've read the book.'

Hebrew

b. karati (*et) $\check{\text { se}}=$ susim oxlim kaš

I.read ACC COMP $=$ horses eat straw

'I've read that horses eat straw.' Hebrew

However, Hebrew CPs used as titles can get case marking (15), which shows that they must be DPs.

$$
\begin{aligned}
& \text { karati et } \quad \text { [oreax nata lalun] } \\
& \text { I.read ACC guest turned to.stay, } \\
& \text { 'I've read A guest came for a night }{ }^{8} \text {.' }
\end{aligned}
$$

Hebrew

The literature converges on that a category-defining head $\mathrm{n}^{0}$ must be present in a DP, see a.o. Marantz (1997), Arad (2003), and Harley (2014). Accordingly, I posit the following structure for a title DP with an underlying XP (16). I assume that gender features are carried by $\mathrm{n}^{0}$, following Lowenstamm (2008) and Kramer (2015), while number is a feature of $\mathrm{Num}^{0}$, following Ritter (1991, 1992, 1995) and the ensuing literature.

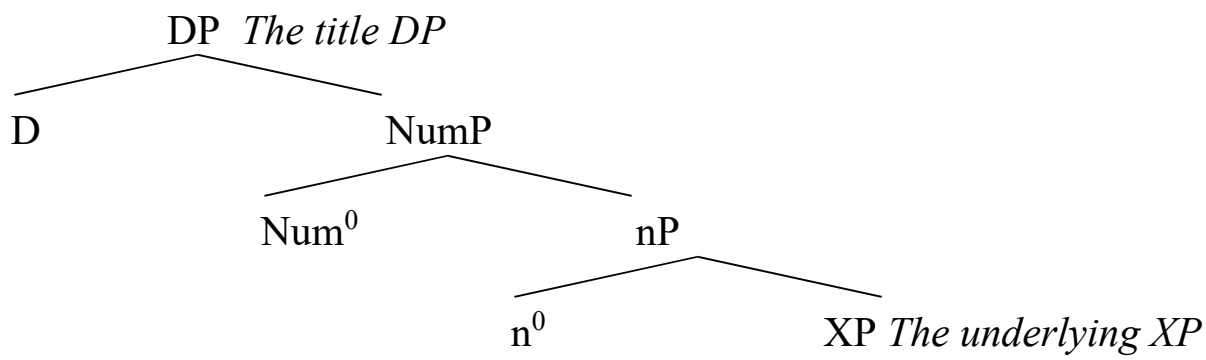

It can be objected to this, however, that in languages where title DPs trigger agreement more or less in the same manner as their underlying DPs do, as we have seen for Russian in (1b), positing an extra DP layer is unnecessary. Nevertheless, language-specific evidence for such a move can be marshalled for Russian as well. First, the behavior of plain coordinated DPs is different from that of coordinated DPs used as titles as the contrast between (17a) and (17b) shows. While coordinated regular DPs, regardless of their animacy, obligatorily trigger plural agreement on the verb (17a), title DPs fail to do so when they are inanimate (17b).
a.
vojna i
$\operatorname{mir} \quad \mathrm{v}$
$\mathrm{v} \quad$ ančurii
Anchuria
menja ne
war and
peace
interesu-jut/
*interesu-jet
interest-PRS.3PL
interest-PRS.3SG
'The war and the peace in Anchuria don't interest me.'
b. vojna i
mir sto-it/
*sto-jat
na
war and peace stand-PRS.3SG/*stand-PRS.3PLon
'War and Peace stands on the upper shelf.'

\begin{tabular}{ll}
\multicolumn{2}{c}{ Russian } \\
verxnej & polke \\
upper & shelf \\
& Russian
\end{tabular}

Second, some nouns change the allomorph of a case marker when used as a title: for instance, for the noun 'nose', the regular allomorph of the prepositional case marker $-u$ only allows the body

\footnotetext{
${ }^{8}$ A novel by Shmuel Yosef Agnon. The standard English translation of the title, A Guest for the Night, does not reflect the fact that the title is actually a sentence.
} 
part reading (18a), while the default allomorph $-e$, which is normally incompatible with the lexeme nos 'nose', allows for the DP to be interpreted as a title $(18 \mathrm{~b})^{9}$.

a.

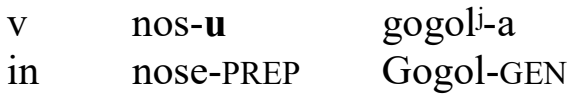

'in Gogol's nose' (only the body part reading)

b. ?v nos-e gogoli ${ }^{\mathrm{j}}$-a

in nose-PREP Gogol-GEN

'in Gogol's Nose' (only the title reading)

Russian

Russian

Finally, the behavior of animate numeral phrases is different in titles. While normally they decline depending on the animacy of the underlying DP, see the contrast between troix 'three.ACC (animate)' and troje 'three.NOM/ACC (inanimate)' (19a, c), animate numeral phrases in titles allow the inanimate declension $(19 b, d)$.
ja vstretil sevodnia
I met today
a. ja
troix/
*troje
'I met three persons today.'
b. $\quad$ ja
čital troje
read three.ANIM.NOM
three.ANIM.GEN/ACC/ *three.INAN.NOM
'I've read Three Men in a Boat.'
met today
$/ *$ tri tovarišča
three.NOM comrade.QNT
'I met three comrades today.'
$\operatorname{trij}^{\mathrm{j}} \mathrm{X}$
v odnoj lodke
Russian
three.ACC.PL comrade.ACC.PL
d. ja čital trijox tovariščej
I read three.acc comrade.ACC.PL three.NOM
'I've read Three Comrades.'

$\begin{array}{ll}\text { /tri } & \begin{array}{l}\text { Russian } \\ \text { tovarišča } \\ \text { three.NOM }\end{array} \\ & \begin{array}{l}\text { comrade.QNT } \\ \text { Russian }\end{array}\end{array}$

Accordingly, to be able to account for such facts, I assume that the structure in (16) with an additional DP and nP layer is present in Russian as well. In particular, based on the arguments in Pereltsvaig (2007), I assume that definite nominal expressions in Russian do project the DP despite the absence of overt articles.

3.2. EXPLANING THE VARIATION. Should an $\mathrm{nP}$ uniformly be a phase, as much of the literature assumes, see e.g. Marantz (2007), Embick \& Marantz (2008), and Kramer (2015), the prediction of the proposed structure in (16) is that any feature of the underlying DP will not be visible to the syntax. However, we have seen in Section 2 that in many languages some or all the features (such as number, gender, or declension type) remain visible. Consequently, we are forced to assume that the $\mathrm{nP}$ layer is to some extent transparent to case assignment and agreement processes, contrary to the assumption about the phasehood of the nP.

Therefore, in some languages $\mathrm{nP}$ is not a phase, and the features of the underlying DP remain visible to the syntax. Technically, "visibility" may mean either that the number and gender values of the additional $\mathrm{nP}$ layer remain unvalued, and so a higher probe must reach below it. Alternatively, a feature percolation mechanism must be responsible for transmitting the number and gender features of the underlying DP upstairs. Me need to assume that case

\footnotetext{
${ }^{9}$ I owe this observation to Anna Urmanchieva (p.c.).
} 
transmission and number/gender percolation are separate processes in order to account for the contrast between type IV languages, where book titles are accessible both to case assignment and agreement as the Russian sentence in (10b) showed, and type III languages where number agreement is impossible or disprefferred as was illustrated by the German sentence in (9b).

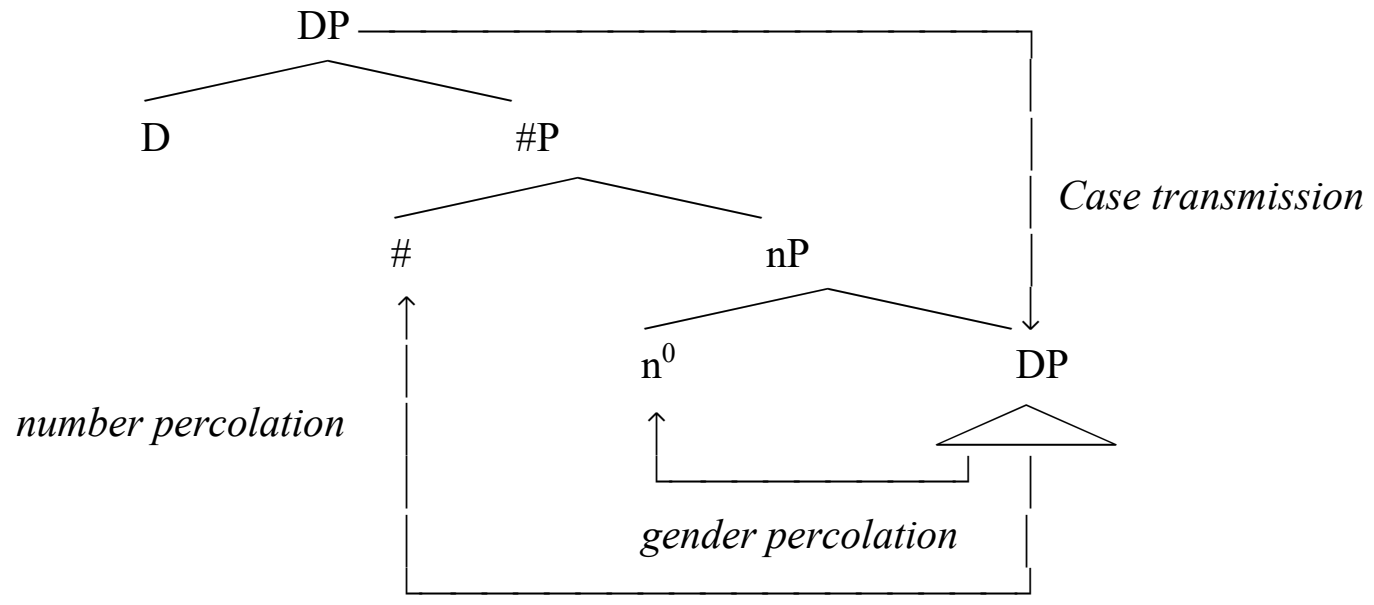

As far as number and gender percolation is concerned, all the 3 Slavic languages in the sample require both, while Armenian lacks grammatical gender. The language sample is too small at present to reach any meaningful conclusions about whether the uniform behavior of the Slavic languages has a principled reason.

4. Functional DPs as titles. So far, we have focused on the properties of lexical DPs. Surprisingly, the properties of functional DPs qua titles are significantly different: even in languages that normally allow lexical DPs to trigger agreement and to bear their natural case (i.e. the case that their underlying DPs would get), for functional DPs this is considerably restricted, and, in the limiting case of personal pronouns, fully impossible. In this section, I address the behavior of functional DPs qua titles and advance a proposal that explains the failure of personal pronouns to participate in agreement and case assignment.

4.1. LOSS OF CASE MARKING AND AGREEMENT WITH PERSONAL PRONOUNS. Even in languages that allow titles with underlying lexical DPs to trigger non-default agreement, personal pronouns are unable to interact with the ambient clause. Person and number features must not percolate to the title DP to participate in AGREE: in (21a), this is illustrated for the Russian 1st person singular pronoun $j a$, which, in the capacity of a title may only trigger the 3 sg agreement. The sentence in (21b) demonstrates that person ${ }^{10}$ or number features cannot percolate separately: while the underlying DP of the title is $m y$ ' we', neither the 1st person feature, nor the plural may show up on the verb: it is the default $3 \mathrm{sg}$ that wins out.
a. ja klavdij stoit/*stoju na polke
I.NOM Claudius.NOM stand.3SG/*stand.1SG on shelf
'I, Claudius stands on the shelf.'
b. $\quad$ my stoit/*stoim/*stoju/*stojat
we $\quad$ stand. $3 \mathrm{SG} / *$ stand.1 $\mathrm{sG} / *$ stand.1 PL/*stand.3PL on shelf
'We stands on the shelf.'
Russian

\footnotetext{
${ }^{10}$ Admittedly, I am adopting here a very naïve theory of pronominal features. The point remains valid if one uses a more sophisticated one, e.g. such as that of Nevins' (2007) or of Harbour's (2016).
} 
Pronouns, in the capacity of titles, are indeclinable, to the extent that they can be used in a sentence at all: Speakers often prefer to use the construction 'novel/book/etc $\mathrm{X}$ ' in these situations.
a. ja čital ja klavdij
I read I.NOM Claudius.NOM
'I've read I, Claudius.'
b. ja čital my /
'I've read $W e$.'
I read we.NOM we.ACC
c. ja čital ono/ *jevo
I read it.NOM/it.ACC
'I've read It.'
d. ich hab wir/*uns gelesen
I have we.NOM/we.ACC read.PRTC
'I've read We.'

$\begin{array}{ll}* \text { menia } & \text { klavdija }^{11} \\ \text { I.ACC } & \text { Claudius.ACC } \\ & \text { Russian }\end{array}$
Russian
Russian
German

4.2 LOSS OF THE DECLENSION CLASS. Some languages are able to convert pronouns into regular nouns and decline them as abstract nouns of the given phonological shape. For instance, in Finnish, the regular accusative of the pronoun me 'we' is meidät, Karlsson (1999:136). However, in the capacity of a title, $m e$ 'we' can only receive the regular nominal genitive-accusative ${ }^{12}$ suffix $-n(23 \mathrm{a})^{13}$. For the pronoun $h \ddot{a} n$ 's/he, it' where the accusative hänet and the genitive hänen are based on the non-suppletive stem, a sentence with the pronoun title assigned will be highly degraded, and the strategy of embedding the pronoun into the phrase 'novel/book $\mathrm{X}$ ' is virtually the only possible.
a. olen lukenut
AUX.1SG read.PRTC
'I've read $W e$.'
b. ?*olen lukenut
AUX.1SG read.PRTC
'I've read It.' (intended)
c. olen lukenut
AUX.1SG read.PRTC
'I've read the book It.'

$\begin{array}{ll}\text { me-n } & / * \text { meidät } \\ \text { we.NOM-ACC/GEN } & \text { /we.ACC }\end{array}$
hänet/hänen
it.ACC/it.GEN
\begin{tabular}{ll} 
kirjan hän & \multicolumn{1}{c}{ hän } \\
book.ACC/GEN it.NOM
\end{tabular}
Finnish
Finnish
Finnish

Likewise, in Georgian, personal pronouns don't exhibit overt case marking (24a), but when used as titles they do (24b). Nor does Georgian allow plural agreement with a book title, unlike for a regular plural DP subject. This is expected in a language where $\mathrm{nP}$ is a phase.

\footnotetext{
${ }^{11}$ Some speakers allow also the sentence in (i).

(i) ja čital ja klavdij-a

I read I.NOM Claudius-ACC
}

I take this to be a separate phenomenon: the title is reanalyzed as a single noun ja-klavdij I-Claudius: under normal circumstances, in Russian, when two DPs are in apposition, both need to be declined.

${ }^{12}$ In Finnish, the genitive and the accusative are syncretic for most nominals; only certain pronouns morphologically distinguish the two cases, Karlsson (1999).

${ }^{13}$ It is more idiomatic to altogether avoid the need to decline the pronoun in such contexts (i).
(i)
olen lukenut
AUX.1SGread.PRTC
romaanin
novel.ACC/GEN
Me
we.NOM
'I've read the novel $\mathrm{We}$.' 
b. ia me-s k'itxulobs

Ia.NOMI-DAT reads

'Ia reads $I$.'

Georgian

In Ossetic, some of the personal pronouns use a suppletive stem to form the cases other than the nominative, which is illustrated in (25a) for the $1 \mathrm{sg}$ pronoun: its nominative form is $e \check{z}$, whereas the ablative form is men-ej. However, if used as titles, these pronouns attach the regular suffix of the respective case directly to the nominative form (25b).

Iron Ossetic: Allomorphy disappears

a. regular use of the pronoun

menвj eppelədi

I.ABL s/he.praised

'S/he praised me.' b. use as a title

$\begin{array}{ll}\mathbf{k z ̌}-\mathbf{r j}=\text { mən } & \text { eppelədi } \\ \text { I.NOM-ABL=I.DAT } & \text { S/he.praised } \\ \text { 'S/he praised } I \text { to me.' }\end{array}$

4.3. IDEA OF ANALYSIS. I propose that titles of pronouns involve an impenetrable nP layer, which even languages of the Slavic type can use as the last resort ${ }^{14}$. Alternatively, one might argue that the construction 'book X' with a phonologically null noun 'book' is used in such cases, but positing a null noun meaning 'book' seems to be a rather adventurous theoretical move.

The key observation is that titles are anaphoric islands, in terms of Postal (1969): a pronoun in the main discourse may not refer to any material within a title. For instance, the discourse in (26) is ungrammatical on the reading that on 'he' refers to the philosopher's stone, in the same manner as the English translation is. 'Stone' is a masculine noun in Russian, and so has to be referred to by a masculine pronoun.

$\begin{array}{llllll}\text { ja } & \text { pročel garri } & \text { potter-a } & \text { i } & \text { filosofskij } & \text { kamen }_{\mathrm{i}} \\ \mathrm{I} & \text { read Harry } & \text { Potter-ACC } & \text { and } & \text { philosophical } & \text { stone } \\ \text { on } *_{\mathrm{i}} & \text { krasnogo } & \text { cveta } & & & \\ \text { he } & \text { red.GEN } & \text { color.GEN } & & & \end{array}$

'I've read Harry Potter and the Philosopher's Stone ${ }_{i}$. It $*_{i}$ is red.' (intended) Russian

To account for the behavior of pronouns, I propose the following: if a nominal is accessible to case assignment and agreement, all its semantic features are visible on the LF. This proposal is similar in the spirit to the Visibility Condition of Chomsky (1986). Now, if interpretable pronominal features are able to percolate to the higher DP layer, an irreconcilable contradiction with the context arises. In the case of 1 st and 2 nd person pronouns (i.e. titles such as $W e$ or $I$ ) the result will be that a non-participant DP will carry [+participant] feature. For 3rd person pronouns in a title, their index cannot point to an entity from the model in which the ambient sentence is interpreted. The latter assumption is confirmed by the anaphoric islandhood of titles (26).

Thus, the only way to avoid a crash at the LF is to embed the underlying DP in a structure that is non-transparent to agreement. This might be achieved by using a non-transparent $\mathrm{n}^{0}$, or, if this is impossible for some reason, by combining the title with a lexical DP 'book/novel/ etc'.

\footnotetext{
${ }^{14}$ The small differences in the behavior of titles and underlying DPs in Russian discussed in Section 3.1 provide additional evidence in favor of a not completely transparent $\mathrm{nP}$ layer.
} 
If this proposal is on the right track, it provides a uniform explanation for disappearance of case marking and agreement in Russian and disappearance of stem allomorphy in Finnish, Georgian, and Ossetic. To prevent semantic interpretation of pronominal features, a nontransparent nP layer is merged. This immediately excludes non-default agreement. Furthermore, at the stage of derivation when the appropriate allomorph of the case marker is chosen, it is the default one that wins out.

In Russian, the default strategy is to not decline novel nouns that do not naturally fall into one of the open declension classes, Timberlake (2004: 148). On the other hand, Finnish, Georgian, and Ossetic have an option to attach the default allomorph of a case marker directly to a novel stem (modulo phonological conditions), and this way pronominal titles end up being treated as abstract nouns of a given shape.

4.4 OTHER FUNCTIONAL DPS AS TITLES. In this subsection, I briefly examine the behavior of deictics and of quantified expressions in Russian and show that they largely pattern with personal pronouns.

A priori, we would expect deictics to behave very similarly to 3rd person personal pronouns. However, case-marking on deictics is judged still degraded (27a), but it is considerably better than on personal pronouns $(27 \mathrm{~b})$.

$$
\begin{aligned}
& \text { a. ?ja čital tu } \\
& \text { I read that.F.ACC } \\
& \text { 'I've read That one.' } \\
& \text { b. *ja čital jejo } \\
& \text { I read she.ACC } \\
& \text { 'I've read She.' }
\end{aligned}
$$

Russian

Russian

One can tentatively explain the contrast between (27a) and (27b) assuming that deictics, unlike personal pronouns, have a null NP in their structure, as was originally proposed by Wiltschko (1998) and pace Grosz \& Patel-Grosz (2017).

Case marking on other types of underlying functional DPs is judged rather degraded as well. At present, I do not have an explanation for this phenomenon. In (28a), this is illustrated for the n-word nikto 'no one', and in (28b), for the quantifier vse 'all.PL'.
a. ??kritiki
vostorgalis $^{j}$
nikem
critics
admired
no.one.INS
'The critics admired No one.'
b. ??molodjož začityvalas ${ }^{j}$
youth was.engrossed.in.reading
'The youth was engrossed in reading All.'
vsemi
all.INS
Russian
Russian

The same is true for universally quantified DPs: the sentence in (29a) with the universally quantified "each peasant" contrasts sharply with (29b) where the title 'peasant' is a plain DP.
a.
??kritiki
vostorgalis ${ }^{j}$
každym
krestjjaninom xriuškinoj critics admired
every.INS peasant.INS 'The critics admired Every Peasant of Khryushkina's.' Khryushkina.GEN
b. kritiki vostorgalis ${ }^{j} \quad$ krestjjaninom $\times$ r $^{j}{ }^{j}$ uškinoj critics admired peasant.INS Khryushkina.GEN 'The critics admired The Peasant of Khryushkina's.'
Russian
Russian 
To recapitulate, I have shown that case marking and agreement is impossible for titles whose underlying DPs are personal pronouns and provided a semantic explanation for that. It remains a puzzle, however, why case assignment to other functional DPs results in degradedness. I must leave this issue for further research ${ }^{15}$.

5. Conclusion. This paper makes an empirical and a theoretical point. On the empirical side, I've shown that book title DPs exhibit non-trivial morphosyntactic behavior whose full extent is yet to be explored. Languages vary in the extent to which title DPs may get morphological case and trigger verb agreement. However, already at this stage it is clear that, in any given language, DPs form a cline in this respect: lexical title DPs are most likely to behave identically as their underlying DPs, while personal pronouns are completely unable to do so. Other functional DPs fall between these two extremes.

On the theoretical side, I have argued that the cross-linguistic variation in case and agreement properties of titles can be accounted for if one makes a number of natural assumptions. First, I have proposed that an additional nP layer is merged atop of the underlying XP to form a title DP. Second, I have proposed that, contrary to what has been proposed earlier in the literature, languages vary in whether $\mathrm{nP}$ is necessarily a phase. If it is not a phase, it can be penetrable to various syntactic processes including agreement. Third, I have argued that given the standard assumptions about which functional categories host which nominal features, feature percolation is necessary to account for the morphosyntactic properties of titles. A wider implication is that feature percolation may play a role elsewhere in the syntax as well, pace much recent work, e.g. Cable (2010), Heck (2009), Narita (2014).

To account for the inability of titles based on personal pronouns (such as We or It) to be assigned case or to trigger agreement, I have proposed that DPs that participate in these processes necessarily have their interpretable features visible at the LF. Given that titles are anaphoric islands, this leads to a crash in the case of pronouns. I leave for further research the properties of other functional titles. Another issue which that has not been addressed here is whether familiarity with the title affects grammaticality judgments: can it be of any relevance that War and Peace is a familiar title, while Every Peasant is made up?

\section{References}

Arad, Maya. 2003. Locality constraints on the interpretation of roots: The case of Hebrew denominal verbs. Natural Language \& Linguistic Theory 21(4). 737-778. https://doi.org/10.1023/A:1025533719905.

Cable, Seth. 2010. The Grammar of Q: Q-particles, wh-movement and pied-piping. Oxford: Oxford University Press. https://doi.org/10.1093/acprof:oso/9780195392265.001.0001. Chomsky, Noam. 1986. Barriers. Cambridge, Mass: MIT Press.

Chomsky, Noam. 2001. Derivation by phase. In Michael Kenstowicz (ed.), Ken Hale: A life in language. 1-52. Cambridge, MA: MIT Press.

\footnotetext{
${ }^{15}$ Tentatively, an explanation may run as follows. Suppose that my proposal is correct that semantic interpretation necessarily happens if the DP in question is assigned case and/or participates in agreement. Then quantifiers within the title are forced to take scope over the domain in which the truth value of the ambient sentence is evaluated. This leads to a semantic clash, because the binding relationship that has to be established between the quantifier and a variable needs to cross the title boundary. Thus the anaphoric islandhood of the title, which we discussed in Section 4.3 , would be violated. Lexical DPs, on the other hand, behave as proper names with fixed referents. The reasons for the latter phenomenon are not clear at present.
} 
Embick, David \& Marantz, Alec. 2008. Architecture and blocking. Linguistic Inquiry 39. 1-53. https://doi.org/10.1162/ling.2008.39.1.1

Harbour, Daniel. 2016. Impossible persons. Cambridge, MA: MIT Press. https://doi.org/10.7551/mitpress/9780262034739.001.0001.

Harley, Heidi. 2014. On the identity of roots. Theoretical Linguistics 40.3: 225-276. https://doi.org/10.1515/tl-2014-0010.

Heck, Fabian. 2009. On certain properties of pied-piping. Linguistic Inquiry 40. 75-111. https://doi.org/10.1162/ling.2009.40.1.75.

Herrity, Peter. 2000. Slovene. A comprehensive grammar. London \& New York: Routledge.

Karlsson, Fred. 1999. Finnish: An essential grammar. London \& New York: Routledge.

Kholodilova, Maria. 2013. Svojstva veršiny u elementov nazvanij v russkom jazyke. [Head properties of subparts of proper names in Russian.] Handout of a talk at Russian: Construction and lexical semantics approaches. Petersburg, September 11-13, 2013.

Kramer, Ruth. 2015 The Morphosyntax of gender. Oxford: Oxford University Press.

Lowenstamm, Jean. 2008 On little n, $\sqrt{ }$, and types of nouns. In Jutta Hartmann, Veronika Hegedüs \& Henk van Riemsdjik (eds.), The Sounds of silence: Empty elements in syntax and phonology. 105- 144. Amsterdam: Elsevier.

Marantz, Alec. 2007. Phases and words. In S.H. Choe (ed.), Phases in the theory of grammar. 191-222. Seoul: Dong-In Publishing Co.

Matushansky, Ora. 2013. Sorts of proper names. Handout of a talk at Semantics and Philosophy in Europe (SPE) 6, St. Petersburg, June 10-13, 2013

Narita, Hiroki. 2014. Endocentric structuring of projection-free syntax. Amsterdam: Benjamins.

Nevins, Andrew. 2007. The representation of third person and its consequences for Person-Case effects. Natural Language and Linguistic Theory 25:273-313. https://doi.org/10.1007/s11049-006-9017-2.

Patel-Grosz, Pritty \& Grosz, Patrick. 2017. Revisiting pronominal typology. Linguistic Inquiry 48(2). 259-297. https://doi.org/10.1162/ling_a_00243.

Pereltsvaig, Asya. 2007. The universality of DP: A view from Russian. Studia Linguistica 61. 59-94. https://doi.org/10.1111/j.1467-9582.2007.00129.x.

Phillips, Colin, Wagers, Matthew, Lau, Ellen. 2011. Grammatical illusions and selective fallibility in real-time language comprehension. In Jeffrey Runner (ed.), Experiments at the Interfaces. Syntax \& Semantics 37. 153-186. Bingley: Emerald Publications

Postal, Paul. 1969. Anaphoric islands. In Papers from the Fifth Regional Meeting of the Chicago Linguistic Society, ed. by Robert Binnick, Alice Davison, Georgia Green, and Jerry Morgan, 205-239. Chicago: University of Chicago, Chicago Linguistic Society.

Ritter, Elizabeth. 1991. Two functional categories in noun phrases: Evidence from Modern Hebrew. In Syntax and Semantics 25, 37-62. New York: Academic Press.

Ritter, Elizabeth. 1992. Cross-linguistic evidence for number phrase. Canadian Journal of Linguistics/Revue canadienne de linguistique 37(2). 197-218. https://doi.org/10.1017/S0008413100021952.

Ritter, Elizabeth. 1995. On the syntactic category of pronouns and agreement. Natural Language \& Linguistic Theory 13(3). 405-443. https://doi.org/10.1007/BF00992737.

Timberlake, Alan. 2004. A Reference Grammar of Russian. Cambridge: Cambridge University Press. 
Wiltschko, Martina. 1998. On the syntax and semantics of (relative) pronouns and determiners. Journal of Comparative Germanic Linguistics. 2. 143-181. https://doi.org/10.1023/A:1009719229992. 